\title{
Effect of Water Salinity on Seeds Germination of Sterile Oat (Avena sterilis) and Rigid Rye Grass (Lolium rigidum) at Constant or Alternating Temperatures
}

\author{
Khalid S. Alshallash \\ College of sciences, Shaqra University, Saudi Arabia
}

\begin{abstract}
Sterile oat (Avena sterilis) and rigid rye grass (Lolium rigidum) are well known grasses in many parts of the world. They grow in grasslands and arable lands. Both are recorded as serious weeds of arable lands in many countries worldwide. Seeds germination of both species were tested at four levels of water salinity concentrations $(0,100,300,500 \mathrm{mM} / \mathrm{L}$ of NaCl$)$ and five different temperatures (Constant at $8 \mathrm{C}^{\circ}$ or alternating temperatures of; 8/16, 10/18,6/14, 10/20 $\mathrm{C}^{0}$ ). Photoperiods regime of 8 hours darkness and 16 hours of light at the constant temperature was implemented. The same was followed with the alternating temperatures with 8 hours darkness at the lower temperature and 16 hours light with the higher temperature. A. sterilis seeds showed better germination with high significance of $(<00.1)$ than L. rigidum seeds at all tested treatments. The mean number of germinated seeds of A. sterilis was (6) out of (20) seeds /petri dish whereas, it was nearly (3) geminated seeds with L. rigidum. Both species secured the highest germination percentage at level of alternating temperatures of $\left(10 / 20 \mathrm{C}^{\circ}\right.$ ) with $40 \%$ (mean number of germinated seeds was 8 out of 20 seeds / petri dish) for A. sterilis and 25\% (5 out of 20 seeds / petri dish) for L. rigidum. Although $A$. sterilis seeds showed some germination (25\%) at constant temperatures of $\left(8 \mathrm{C}^{\circ}\right), \mathrm{L}$. rigidum seeds were less in favorite of this climatic condition expressing its response to alternating temperatures. Generally, A. sterilis seeds showed better germination responses than L. rigidum seeds at all different level of tested temperatures. Moreover, A. sterilis seeds resist water salinity as high as $100 \mathrm{mM}$ of $\mathrm{NaCl} / \mathrm{L}$ and showed almost $50 \%$ germination especially at its favorite alternating temperature of $\left(10 / 20 \mathrm{C}^{\circ}\right) . \mathrm{L}$. rigidum seeds also showed some resistance to $100 \mathrm{mM} / \mathrm{L}$ of $\mathrm{NaCl}$ giving about $35 \%$ germination. However, both species gave poor germination at higher levels of water salinity of 300 and $500 \mathrm{mM}$ of $\mathrm{NaCl} / \mathrm{L}$ concentrations. Results confirmed that both species seeds germination are in favorite of moderate alternating temperatures condition expressing some resistance to water salinity. This explains both species invasion and persistence in arable lands being reported a serious weedy plant species especially in a Mediterranean climate and subtropical conditions. In addition those results showed some of the two species seed biological aspects, which could contribute to a better control practice of the two species in arable lands.
\end{abstract}

Keywords: Seeds germination, constant, alternating, temperature, salinity, Lolium rigidum, Avena sterilis.

\section{Introduction}

Sterile oat (Avena sterilis) is reported as one the most widespread and harmful weed species in Mediterranean climate (Castellanos-Frias, 2014). It is also considered to be common grass weed of cereals in Mediterranean countries (Dimakakos, 1983) and India (Balyan, et al., 1991) and North America (Carlson and Hill, 1985) and in Europe and Australia (Torner, et al., 1984). Chaudhary 
(1989) confirmed also the present of this species as serious weed of cereals in Saudi Arabia. Lolium rigidum is also considered as a major weed in regions of Mediterranean climate worldwide (Monaghah, 1980; Jauzein and Monteguat, 1983; Recasens et al., 1997). It is also reported to be major weed problem in Spain (Garcia Baudin, 1982). Chauhan et al., (2006) confirmed its present in southern Australia. Chaudhary (1989) confirmed that $L$. rigidum is the most serious narrow-leaf weed in cereal fields in Saudi Arabia. It has been also recorded in a check list of weed flora in Saudi Arabia (Elghazali and Alsoqeer, 2013).

Germination is a crucial stage in the life cycle of the plant (khan and Gulzar, 2003). Temperatures affect the percentage and rate of germination through its effects on seed deterioration, loss of dormancy and germination process itself (Roberts, 1988). Temperature, light, water and salinity thought to interact at the soil-atmosphere interface to regulate seed germination (Jian-guo et al., 2012). Moreover, It has been reported that fluctuation in temperatures stimulate seed germination (Thompson and Grime, 1983). Soil temperature and salinity are the most important factors control seed germination in the saline soils of arid and semi-arid regions (khan and Unger, 1999). Salinity generally causes reduction in germination rate and delay germination. Salinity in soil or water is a major stresses to seed germination (Shannon 1998). Salinity stress is a major limiting factor for seed germination (Ozdener and Kutbay, 2008).

This paper investigates the effect of constant or a range of fluctuating temperatures and a range of salinity concentrations on seed germination of a very well known and serious grass weed species. The range of implemented temperatures in this experiment is related to the climatic conditions where the species of sterile oat and rigid rye grass present is reported. Seed germination is a major stage that result in the degree of presence of the plants. Understanding the biological aspect of seed germination and factors related to it contribute to the anticipation of expected populations. The range of water salinity percentage applied in this research paper followed the range applied by Ozdener and Kutbay, 2008 in their study on Spergularia marina.

\section{Martials and methods}

Seeds of sterile oat (Avena sterilis) and annual ryegrass (Lolium rigidum) were collected in the late spring of 2014 from wheat farm in Aljouf area north of Saudi Arabia. Seeds were kept in glass jars and refrigerated in dry condition at $4 \mathrm{C}^{\circ}$ to maintain their viability. Experiment were carried out in a five cool incubators representing the five level of temperatures under investigation (constant at 8 $\mathrm{C}^{\circ}$ or alternating temperatures at; 8/16, 10/18, 6/14, 10/20 C ${ }^{\circ}$ ). Programmable cool incubators is the persuasive solution for stable incubation processes. They are set to create daily cycles of heating and cooling regimes as well as light and dark rotation. Cooled incubators also work reliably in a range of -5 ${ }^{\circ} \mathrm{C}$ to $100{ }^{\circ} \mathrm{C}$ and are characterized by their high temperature precision.

Darkness was provided for 8 hours at the lower temperature and light was present for 16 hours at the higher temperature for the whole time of the experiment. Photo periods regime of $(8 / 16 \mathrm{~h})$ was also applied when constant temperatures of $8 \mathrm{C}^{0}$ was applied. Salty solution was prepared at four levels of concentration of $\mathrm{NaCl}(0,100,300,500 \mathrm{~mm} / \mathrm{L}$ $\mathrm{NaCl})$. Seeds were placed in a double layers of filter paper in a sterilized petri dishes with 20 seeds/petri dish and four replicates. GA3 solution at $200 \mathrm{ppm}$ was added at amount of $10 \mathrm{ml} /$ petri dish to the seeds of both species at the beginning of the experiment for 48 hours 
to stimulate their germination and break seed dormancy where exist. Enough moisture of the applied solutions were maintained daily by adding few drops of the solutions daily. Petri dishes were monitored daily for 60 days to record germination. The experiment was applied in a 2 factors randomized complete block design with four replicates of each treatment. Final record of germination was analyzed using the statistical program Genstat to determine the significance between treatments through ANOVA and Least significant difference (LSD).

\section{Results}

Analysis of the final germination record showed the following findings:

\section{Time taken for germination:}

$80 \%$ of seeds germination of both species occurred within the first 20 days and germination stopped after 35 days from experiment commencement. There was not any germination after 35 days although the experiment was left for sixty days. This showed early response of both species seed to the factors under study. It also confirmed high seed viability and seed response to the treatment by GA3 solution being added as dormancy breaking agent and as a germination stimulants.

\section{Overall germination:}

\section{1) Overall germination of the Species:}

Avena sterilis seeds germinated generally in significantly higher percentage than L. rigidum seeds as shown in (figure 1) suggesting better response of $A$. sterilis seeds at different factors under investigation. The low germination in both species is referred to the absent of response in both species seeds to some water salinity concentrations and temperatures level under investigation.

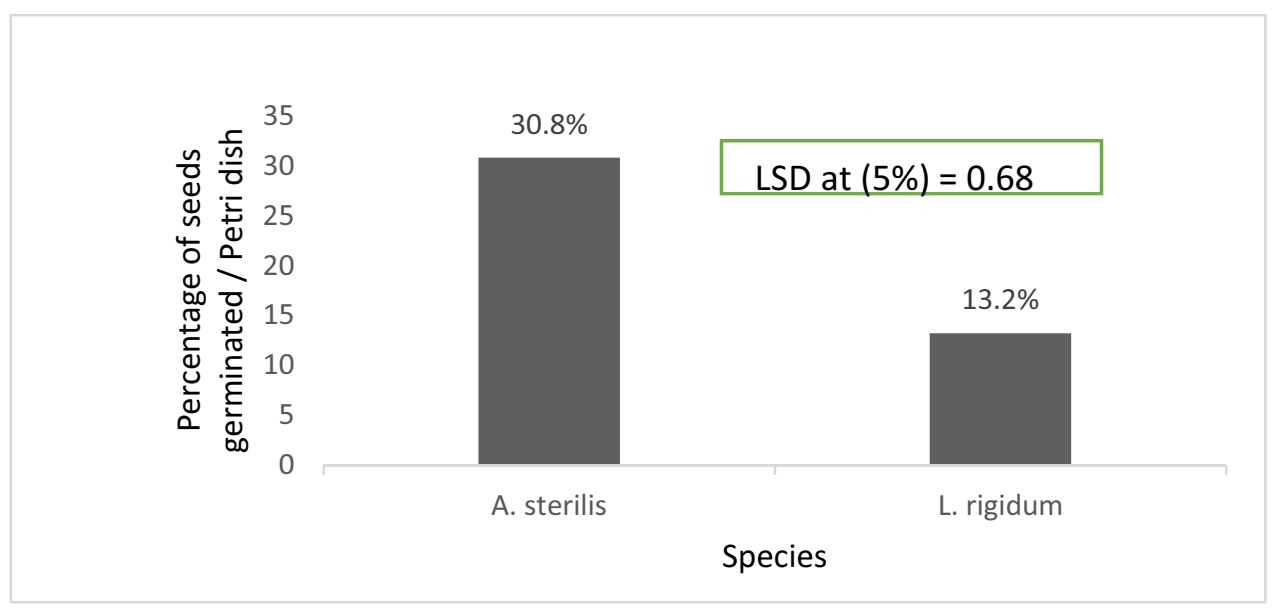

Fig 1. General germination responses of the species.

\section{2) Effect of temperatures on seeds germination:}

A. sterilis showed better germination at different levels of temperatures than $L$. rigidum giving its highest germination percentage at alternating temperature $(10 / 18 \mathrm{C}$ $\left.{ }^{0}\right)$ and $\left(10 / 20 \mathrm{C}^{0}\right)$ with $(8 / 16 \mathrm{H})$ photoperiod. L. rigidum showed better germination at 10/20
$\mathrm{C}^{0}$ with $(8 / 16 \mathrm{H})$ photoperiod. Both species favored higher temperatures of (10/18 and $10 / 20 \mathrm{C}^{0}$ ) for germination suggesting species adaptation to warm condition. Germination of both species at constant of $\left(8 \mathrm{C}^{0}\right)$ did not differ significantly from low alternating temperatures of $\left(6 / 14\right.$ and 8/18 $\left.\mathrm{C}^{0}\right)$ whereas, it did differ from higher alternating temperature of $\left(10 / 18\right.$ and $\left.10 / 20 \mathrm{C}^{0}\right)$. Although A. sterilis 
seeds showed high germination at constant temperatures of $\left(8 \mathrm{C}^{\circ}\right)$, L. rigidum seeds were less in favorite of this climatic condition expressing its response to alternating temperatures. Figure 2 represents both species seeds germination responses to different level of temperatures

examined.

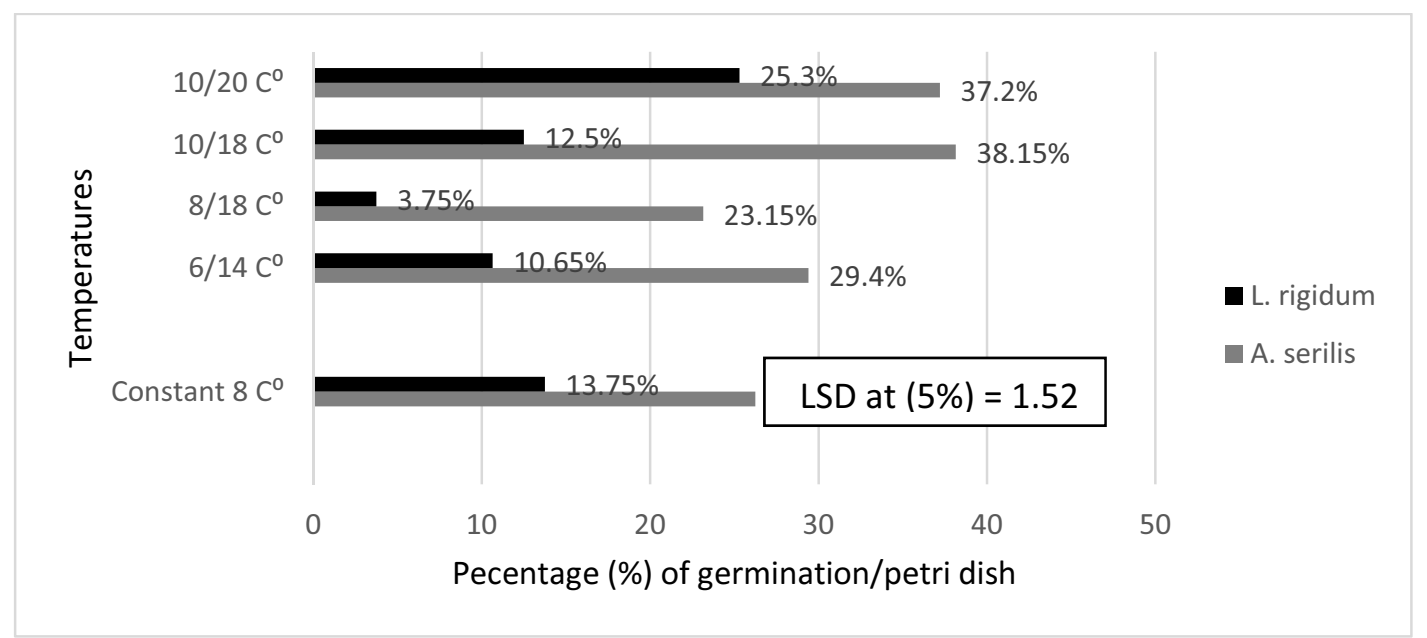

Fig. 2. Germination responces of the species to different level of temperatures.

\section{3) Effect of water salinity on seed germination:}

Water Salinity inhibited germination of both species significantly. Seeds Of both species were not able to germinate at 300 and $500 \mathrm{mM} / \mathrm{L}$ of $\mathrm{NaCl}$ concentrations. However, at $100 \mathrm{mM} / \mathrm{L}$ of $\mathrm{NaCl}$ concentration of salt some germination occurred, A. sterilis seeds resist water salinity as high as $100 \mathrm{mM}$ of
$\mathrm{NaCl} / \mathrm{L}$ and showed almost $50 \%$ germination especially at its favorite alternating temperature of $\left(10 / 20 \mathrm{C}^{\circ}\right)$. L. rigidum seeds also showed some resistance to $100 \mathrm{mM} / \mathrm{L}$ of $\mathrm{NaCl}$ giving about $35 \%$ germination. Fig. 3 illustrates germination responses of both species at different concentrations of water salinity.

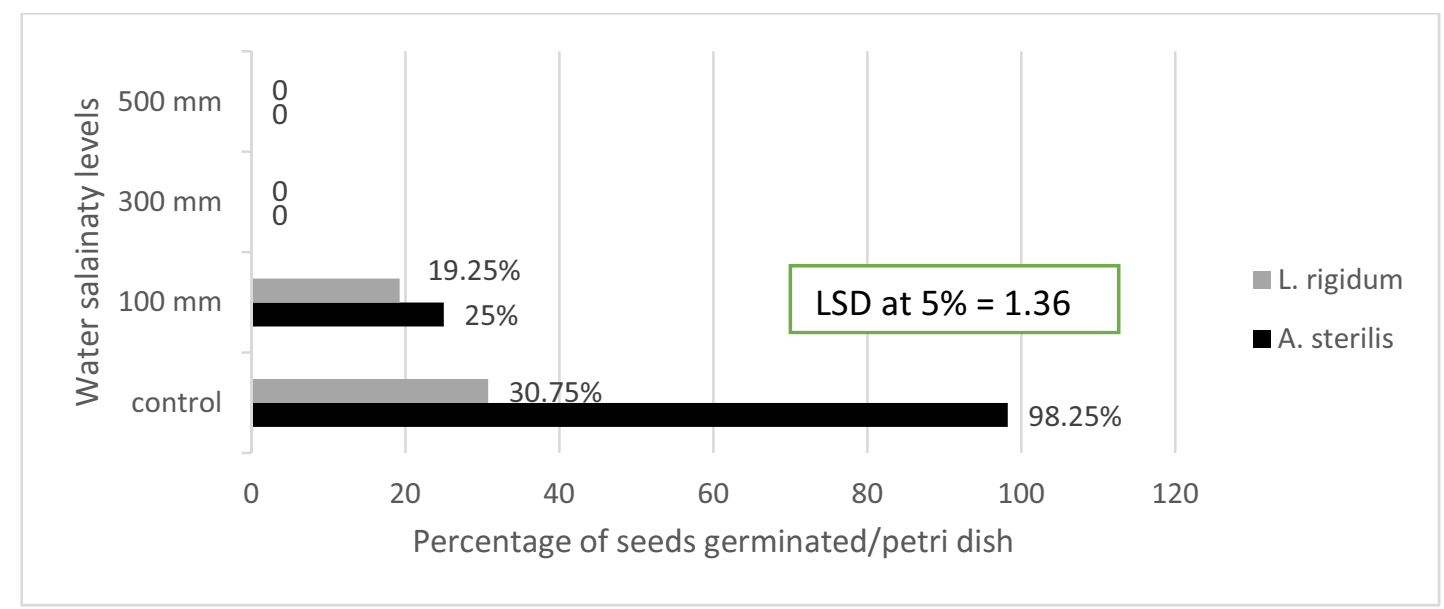

Fig. 3. Germination responses at different salinity levels. 


\section{4) Interacted effect of variation in temperature and water salinity concentrations on seeds germination:}

Statistical analysis showed interaction effects. Both species showed better germination at wormer temperature of $10 / 20$ even when moistened with $100 \mathrm{~mm} / \mathrm{L}$ of $\mathrm{NaCl}$ concentration. The interaction effects of temperature and water salinity on germination confirmed the effects of the two factors individually. Table 1 and 2 present some of the interaction effects on both species.

Table 1. Effect of interaction between temperature and water salinity level on percentage $(\%)$ of germinated seeds of $\boldsymbol{A}$. sterilis / petri dish.

\begin{tabular}{|l|l|l|l|l|}
\hline & \multicolumn{4}{|l|}{ Water salinity $(\mathrm{mM} / \mathrm{L})$} \\
\hline Temperatures $\left(\mathrm{C}^{0}\right)$ & 0 & 100 & 300 & 500 \\
\hline 8 & $100 \%$ & $5 \%$ & $0 \%$ & $0 \%$ \\
\hline $6 / 14$ & $100 \%$ & $17.5 \%$ & $0 \%$ & $0 \%$ \\
\hline $8 / 16$ & $91.25 \%$ & $1.25 \%$ & $0 \%$ & $0 \%$ \\
\hline $10 / 18$ & $100 \%$ & $52.50 \%$ & $0 \%$ & $0 \%$ \\
\hline $10 / 20$ & $100 \%$ & $48.75 \%$ & $0 \%$ & $0 \%$ \\
\hline LSD at $(0.05 \%)$ & 3.04 & \multicolumn{4}{|l}{} \\
\hline
\end{tabular}

Table 2. Effect of interaction between temperature and water salinity level on percentage (\%) of germinated seeds of $L$. rigidum / petri dish.

\begin{tabular}{|l|c|c|c|c|}
\hline & \multicolumn{4}{|c|}{ Water salinity (mM/L) } \\
\hline $\begin{array}{l}\text { Temperatures } \\
\left(\mathrm{C}^{0}\right)\end{array}$ & 0 & 100 & 300 & 500 \\
\hline 8 & $30 \%$ & $25 \%$ & $0 \%$ & $0 \%$ \\
\hline $6 / 14$ & $28.75 \%$ & $13.75 \%$ & $0 \%$ & $0 \%$ \\
\hline $8 / 16$ & $12.5 \%$ & $0 \%$ & $2.5 \%$ & $0 \%$ \\
\hline $10 / 18$ & $25 \%$ & $21.25 \%$ & $3.75 \%$ & $0 \%$ \\
\hline $10 / 20$ & $57.50 \%$ & $36.25 \%$ & $7.5 \%$ & $0 \%$ \\
\hline LSD at $(0.05 \%)$ & \multicolumn{5}{|c|}{3.04} \\
\hline
\end{tabular}

\section{Discussion}

Higher germination rate of Avena sterilis seeds than L. rigidum seeds although both seed samples of the same origin and the same time of collection and storage condition can be attributed to the variation between the two species in seed structure as well as dormancy loss ability. Both species seeds germinated at the range of temperatures examined expressing their ability to germinate in a wide range of climatic conditions. However, alternating temperatures proved to have a significant effect at wormer condition in both species. Many species seeds found to response to various amplitudes of temperature fluctuation (Thompson and Grime, 1983). CastellanosFrias, et al. (2014) reported $A$. sterilis to have a high adaptation in a global geographical distribution with a wide range of temperatures. L. rigidum is also reported to be adapted to a broad range of temperatures for germination between 12 and $30^{\circ} \mathrm{C}$ (Turner, et al., 2001). However, low germination rates of both species at some temperatures can be an effect of water salinity especially at high concentration levels of 300 and $500 \mathrm{mM} / \mathrm{L}$ of $\mathrm{NaCl}$. The germination responses of both species are in line with the pattern of temperatures in the winter of Saudi Arabia which can be used in the predication of both amount and time of their germination.

Results confirmed both species sensitivity to water salinity with low germination at 100 $\mathrm{mm}$ of $\mathrm{NaCl}$ concentration and poor germination of both species with higher levels of concentration of $\mathrm{NaCl}$. These finding confirmed by findings of (Chauhan, et al., 2006) reporting decrease in germination of $L$. rigidum seeds by $50 \%$ above $40 \mathrm{mM} / \mathrm{L}$ of $\mathrm{NaCl}$ concentration. Watt (1983) reported a low germination of $L$. perenne with the increase of salinity in soil or water. The inhibitory effects of $\mathrm{NaCl}$ on seed germination could be attributed to its direct effect on embryo growth (Altaisan, 2010). PoljakoffMayber et al. (1994) reported that embryo elongation was strongly inhibited by high levels of $\mathrm{NaCl}$ concentration in irrigation solution. In addition, $\mathrm{NaCl}$ increases the osmotic potential of the media causing inhibitory effects on seed imbibition (Almansouri et al., 2001). Reduction in germination by high salinity levels has been described by numerous authors (Altaisan, 2010). According to Mayer and Poljakoff- 
Mayber (1989) salt leads to absence of embryo energy to start germination process, as energy was obtained by increments in the respiratory pathway after the ambition and in low levels of water potential tax water absorption was processed slowly. Salinity stress affect seed germination through osmotic effects (Wellbaum et al., 1990) and salt induced inhibition of seed germination due to osmotic stress or ion toxicity (Faheed, et al., 2005).

The increase in both species ability to resist salty conditions, could reflect their adaptation to a wider range of temperatures. This assumption could be supported by (Chauhan et al., 2006) findings who reported some germination of L. rigidum seeds even when watered with a solution at $160 \mathrm{mM} / \mathrm{L}$ of $\mathrm{NaCl}$ concentration. So, the development of weed control practices should limit the species ability to produce high seed return as this will result in an intensive plant populations. High adaptation of both species to a wide range of temperatures and a degree of water salinity level explain their presence in a wide range of climatic conditions. This should be taken into account in their control strategy.

\section{References}

Almansouri, M., Kinet, J.M. and Lutts, S. (2001) Effect of salt and osmotic stresses on germination in durum wheat (Triticum durum), Plant and Soil, 231: 243-254. http://dx.doi.org/10.1023/A:1010378409663.

Al-Taisan, W. A. (2010) Comparative effects of drought and salt stress on germination and seedling growth of Pennisteum divisum (Gmel.) Henr, American Journal of Applied Sciences, 7 (5): 640-646.

Balyn, R.S., Malik R.K., Panwar, R.S. and Singh, S. (1991) Competitive ability of winter wheat cultivars with wild oats (Avena ludoviciana), Weed Science, 39: 154-158.

Carlson, H.L. and Hill, J. E. (1985) Wild oat (Avena fatua) competition with spring wheat: Plant density effects, Weed Science, 33:176-181.

Castellanos-Frias, E., Garcia de Leon, D., Pujadas-Salva, A., Dorado, J. and Gonzalez-Andujar, J. L. (2014) Potential distribution of Avena sterilis in Europe under climate change, Annals of applied Biology, 165: 53-61.
Chaudhary, S. A. (1989) Grasses of Saudi Arabia, Safire Press:Riyadh.

Chauhan, B.S, Gill, G. and Preston, C. (2006) Influence of environmental factors on seed germination and seedling emergence of rigid rye grass (Lolium rigidum), Weed Science, 54: 1004-1012.

Damanakis, M.E. (1983) Weed species in wheat fields in Greece-1982, 1983 survay, Zizaniology, 1: 85-90.

Elghazali, E. B. and Alsoqeer, A. A. (2013) Acheklist of the Weed Flora of Qassim Region, Saudi Arabia, Australian Journal of Basic and Applied Sciences, 7 (2): 900-905.

Faheed, F.A., Hassanein, A.M. and Azooz, M.M. (2005) Gradual increase in $\mathrm{NaCl}$ concentration overcomes inhibition of seed germination due to salinity stress in Sorghum bicolor L., Acta. Agronomica Hungarica, 53: 229-239.

Gracia Baudin J.M. (1982) Importancia de los 'vallicos' en los cereals de invierno espanoles, Boleitin Del Servicio de Plagas, 8:179-184.

Jauzein, P. and Montegut, J. (1983) Graminees (Poaceae) Nuisibles en Agriculture, EcoleNationale Superieure DHoticulture de Versailles, Versailles, France.

Khan, M.A. and Gulzar, S. (2003) Germination responses of Sporoblus ioclados: a saline desert grass, J. Arid Environ, 53: $387-394$.

Khan, M.A. and Ungar, I.A. (1999) Seed germination and recovery of Triglochin maritime from salt stress under different thermoperiods, Great Basin Nat, 59: 144-150.

Mayer, A.M. and Poljakoff-Mayber, A. (1989) The germination of seeds, Fourth Edition, Pergamon Press, London.

Monaghan, N.M. (1980) The biology and control of Lolium rigidum as a weed of wheat, Weed Research, 20: 117-121.

Ozdener, Y. and Kutbay, H.G. (2008) Effect of salinity and temperature on the germination of Spergulaia marina seeds and ameliorating effect of ascorbic and salicylic acids, Journal of Environmental Biology, 29 (6): 959-964.

Poljakoff-Mayber, A., Somers, G.G., Werker, E. and Gallagher, J.L. (1994) Seeds of Kosteletzkya virginica (Malvaceae): their structure, germination and salt tolerance, II. Germination and salt tolerance, American Journal of Botany, 81: 54-59.

Recasens, J., Taberner, A. and Izquierdo, J. (1997) Lolium rigidium Gaud. En cultivos de cereals. In: Biologia de Las Malas Hierbas de Espana (eds X Sans and C FernandezQuintanilla), 49-64. Phytoma Espana, Valencia, Spain.

Roberts, E. H. (1988) Temperature and seed germination. In: long SP, Woodward FI, eds. Plants and temperature. Symposia of the Society of Experimental Biology, Cambridge: Company of Biol-ogists Ltd, 42: 109-132. 
Shannon, M.C. (1989) Adaptation of plant to salinity, $A d v$. Agron, 60: 75-119.

Thompson, K. and Grime, J.P. (1983) A comparative study of germination responses to diurnally-fluctuating temperatures, Journal of Applied Ecology, 20: 141-156.

Torner, C., Fernandez-Quintanilla, C. and Navarrete, L. (1984) Tolerance and competitive ability of winter cereal cultivars in the presence of Avena sterilis. Procedings $3^{\text {rd }}$ EWRS symposium on Weed problems in the Mediterranean area, Oeiras, Portugal: 109-115.

Turner, N. C., Thomson, C.J. and Rawson, H. M. (2001) Effect of temperature on germination and early growth of subterranean clover, cape weed and Wimmera ryegrass, Grass and forage science, 56: 97-104.
Welbaum G.E., Tissaoui, T. and Bradford, K.J. (1990) Water relations of seed development and germination in muskmelon (Cucumis melo L.). III. Sensitivity of germination to water potential and abscisic acid during development, Plant Physiology, 92: 1029-1037.

Watt, T.A. (1983) The effects of salt water and soil type upon the germination, establishment and vegetative growth of Hocus lanatus and Lolium perenne, The New phytologist, 94: $275-291$.

Xue, J.G, Wang, X.G., Du, X.G., Mao, P.S., Zhao, L. and Han, J.G. (2012) Influence of salinity and temperature on the germination of Hedysarum scoparium Fisch. Et Mey, African Journal of Biotechnology, 11 (14): 3244-3249. 


\section{دراسة لتأثير تراكيز مختلفة من ملوحة الماء على إنبات بذور الراي الصلب والثوفان البري في ظروف درجات الحرارة الثابتة والمتغيرة}

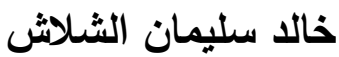

\section{كلية العلوم، جامعة شقراء، الرياض، المدلكة العربية السعودية}

المستخلص. أعثاب الراي الصلب والثوفان البري هي أعثاب تتمو في أجزاء مختلفة من العالم سواء في البيئات النباتية البرية أو المزروعة، وقد سجلت كأعثاب ضابنارة في المناطق الزراعية في العديد من دول العالم. تم في هذه الدراسة اختبار قدرة بذور الراي الصلب والثوفان البري بعد ترطيبها بمحلول حامض

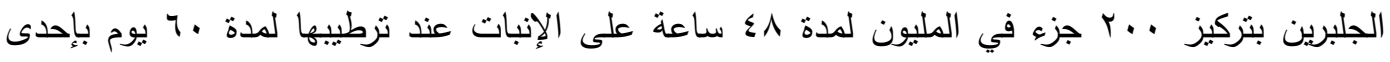

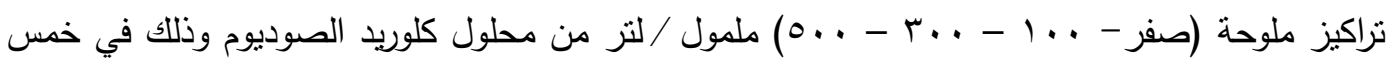

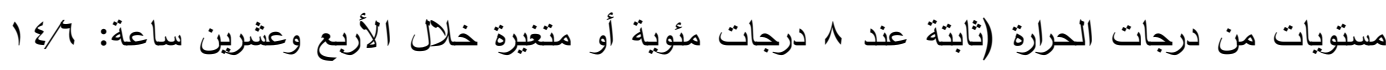

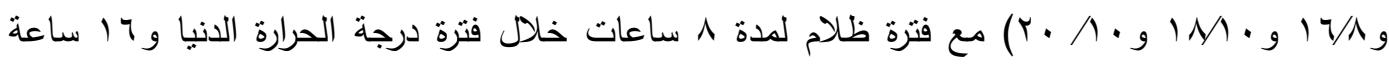
إضاءة خلال فترة درجة الحرارة العليا، وبنفس النظام ^ درجات ظلام و 17 إضاءة مع درجة درة الحرارة الثابتة. بشكل عام كان إنبات بذور الثوفان أفضل بمستوى معنوية عالية (>> + ., •) من بذور الراي في

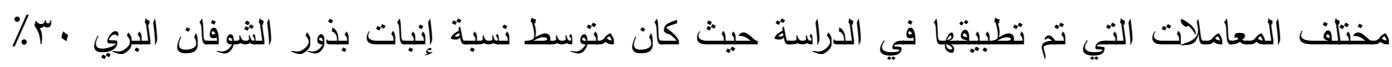

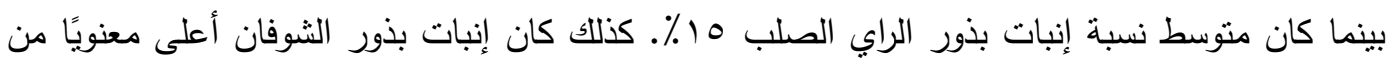

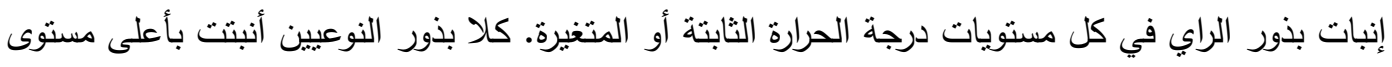

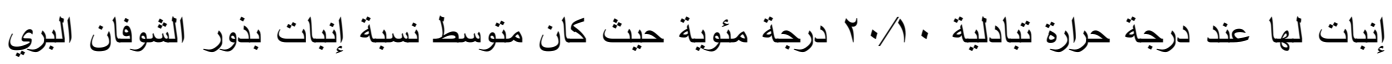

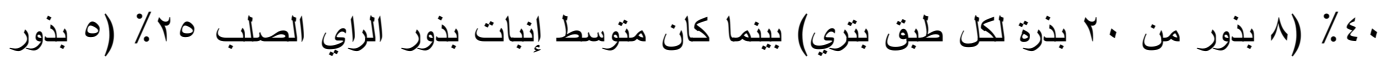

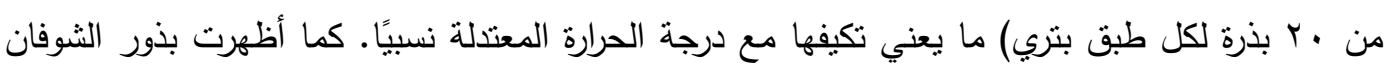
البرية قدرة أفضل من بذور الراي الصلب على الإنبات في ظروف درجة دانة الحرارة الثابتة م درجات مئوية

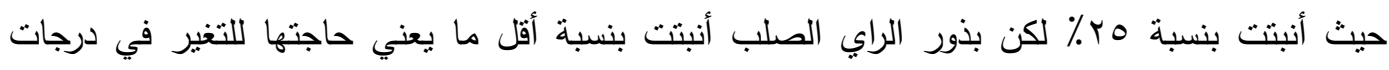

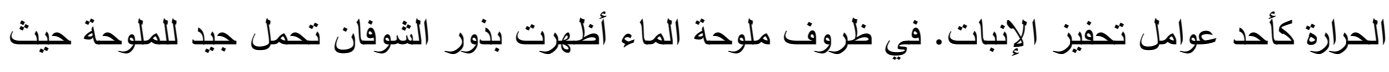

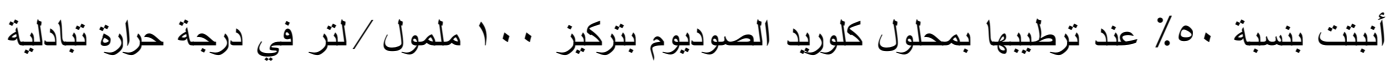

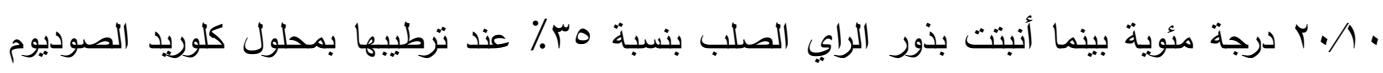

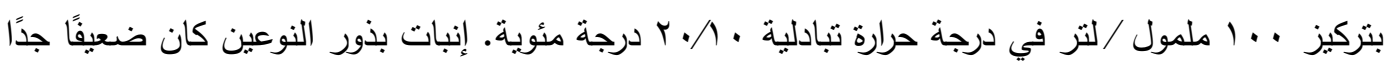

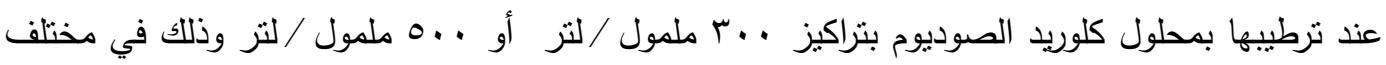


درجات الحرارة التي طبقت. هذه النتائج تؤكد قدرة جيدة لبذور النوعين على التكيف مع مدى واسع من درجات الحرارة المعتدلة وعلى قدرة إنبات جيدة في ظروف ملوحة المياه. كما تفسر النتائج أسباب انتشار

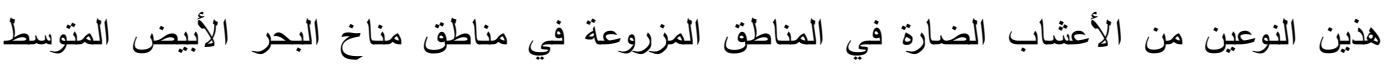
والمناطق تحت الاستوائية، وكذلك انتشارها في مناطق بيئات المياه المالحة. كما تساعد هذه النتائج على العى فهم الخصائص البيولوجية لبذور هذين النوعين ما يساعد على مكافحتها وأخذ ذلك في الاعتبار عند اختيار طرق المكافحة.

الكلمات الدفتاحية: إنبات البذور - درجات الحرارة الثابنة أو المتغيرة - ملوحة الماء - الراي الصلب الثوفان البري. 
